Canadian

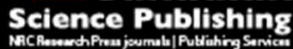

Canadian Geotechnical Journal Revue canadienne de géotechnique

\title{
An approach for modelling volume change of fine-grained soil subjected to thermal cycles
}

\begin{tabular}{|r|l|}
\hline Journal: & Canadian Geotechnical Journal \\
\hline Manuscript ID & cgj-2016-0459.R2 \\
\hline Manuscript Type: & Note \\
\hline Date Submitted by the Author: & 01 -Jan-2017 \\
\hline Complete List of Authors: & $\begin{array}{l}\text { Ma, Qijie; Hong Kong University of Science and Technology, Department of } \\
\text { Civil and Environmental Engineering } \\
\text { Ng, C.W.W.; Hong Kong University of Science and Technology, Department } \\
\text { of Civil and Environmental Engineering } \\
\text { Mašín, David; Charles University in Prague, Faculty of Science } \\
\text { Zhou, Chao; Hong Kong University of Science and Technology, Department } \\
\text { of Civil and Environmental Engineering }\end{array}$ \\
\hline Keyword: & \begin{tabular}{l} 
thermal, cyclic, fine-grained soil, constitutive modelling \\
\hline
\end{tabular} \\
\hline
\end{tabular}

\section{SCHOLARONE ${ }^{m}$}

Manuscripts 


\section{An approach for modelling volume change of fine-grained soil}

\section{subjected to thermal cycles}

3 Authors: Q. J. Ma*, C. W. W. Ng, D. Mašín and C. Zhou

$4 \quad *$ Corresponding author

5 Information of the authors

6 Corresponding author: Mr Q. J. Ma

7 Research student, Department of Civil and Environmental Engineering, Hong Kong University

8 of Science and Technology, Clear Water Bay, Kowloon, Hong Kong.

$9 \quad$ E-mail: qmaah@connect.ust.hk

10 Co-author: $\operatorname{Dr}$ C. W. W. Ng

11 Chair Professor, Department of Civil and Environmental Engineering, Hong Kong University

12 of Science and Technology, Clear Water Bay, Kowloon, Hong Kong.

13 E-mail: charles.ng@ust.hk

14 Co-author: Dr D. Mašín

15 Associate Professor, Faculty of Science, Charles University in Prague, Czech Republic.

16 E-mail: masin@natur.cuni.cz 
17 Co-author: $\operatorname{Dr}$ C. Zhou

18 Visiting Assistant Professor, Department of Civil and Environmental Engineering, Hong Kong

19 University of Science and Technology, Clear Water Bay, Kowloon, Hong Kong.

20 E-mail: czhou@connect.ust.hk 
21 Abstract: In consequence of cyclic heating and cooling about the ambient temperature

22 under drained conditions, normally consolidated and lightly over-consolidated fine-grained

23 soils experience accumulation of irreversible volumetric contraction. Most existing

24 thermo-mechanical models were developed for one heating-cooling cycle and are not

25 suitable for multiple thermal cycles. An approach is proposed to simulate the volume change

26 of fine-grained soil induced by thermal cycles. In the proposed approach, a thermal

27 stabilization line is introduced to control the stabilized volumetric contraction under thermal

28 cycles. Comparison with experimental results shows that the proposed approach can

29 reproduce well the cumulative feature of volumetric contraction of fine-grained soil

30 subjected to thermal cycles.

31 Key words: thermal, cyclic, fine-grained soil, constitutive modelling. 


\section{Introduction}

33 Thermal effects on soil behaviour have drawn attention from researchers throughout the

34 past decades (Campanella and Mitchell 1968; Leroueil and Marques 1996; Hueckel et al.

35 2009; Gens 2010). Under drained conditions, a monotonic temperature increase can induce

36 irreversible volumetric contraction of normally consolidated (NC) and lightly

37 over-consolidated (OC) fine-grained soils (e.g., Baldi et al. 1988; Sultan et al. 2002; Cekerevac

38 and Laloui 2004; Abuel-Naga et al. 2007; Uchaipichat and Khalili 2009; Ng et al. 2016). When

39 subjected to thermal cycles, irreversible volumetric contraction accumulates, and stabilizes

40 within less than 5 thermal cycles (e.g., Campanella and Mitchell 1968; Vega and McCartney

41 2014; Di Donna and Laloui 2015). The accumulation of irreversible volume contraction with

42 thermal cycles is likely due to the degradation of the inter-particle shear strength under

43 elevated temperatures (Campanella and Mitchell 1968; Di Donna and Laloui 2015) and the

44 soil creep (Leroueil and Marques 1996; Vega and McCartney 2014).

45 To model the thermally induced volume change of fine-grained soil, the critical state

46 framework was extended incorporating the shrinkage of yield surface with increasing

47 temperature (e.g., Hueckel and Baldi 1990; Graham et al. 2001; Laloui and Cekerevac 2003).

48 In some other models (e.g., Cui et al. 2000; Abuel-Naga et al. 2007), an extra thermal yield

49 surface was introduced to improve the simulation of over-consolidated soil. It should be

$$
-4-
$$


50 noted that these models simulate well one heating-cooling cycle, but cannot give the

51 cumulative trend of irreversible volumetric contraction with thermal cycles. Although the

52 thermo-mechanical models based on the concept of hypoplasticity can capture the

53 cumulative trend (e.g., Mašín and Khalili 2012; Zhou and Ng 2015), they tend to

54 overestimate the accumulated irreversible volumetric contraction. Di Donna and Laloui

55 (2015) furthered the work by Laloui and François (2009) to account for cyclic thermal loading

56 through modifying the rule governing the plasticity mobilization during cooling.

57 The accumulation and stabilization of irreversible volume contraction of fine-grained soil

58 subjected to thermal cycles can be classified as a kind of shakedown (Collins and Boulbibane

59 2000). The concept of shakedown has been used to model the soil behaviour subjected to

60 mechanical cyclic loading (e.g., Habiballah and Chazallon 2005) and wetting-drying cycles

61 (Nowamooz et al. 2016). Based on the concept of shakedown, an approach is proposed for

62 simulating the volume change of fine-grained soil subjected to thermal cycles, with focus on

63 NC soil. The sign convention used herein is in accordance with soil mechanics, positive for

64 volume decrease and negative for volume increase.

\section{Proposed approach}

\section{Schematic illustration}

67 As suggested by the experimental results on soil volume change under thermal cycles (e.g., 
68 Campanella and Mitchell 1968; Vega and McCartney 2014; Di Donna and Laloui 2015), a

69 thermal stabilization line (TSL) is proposed, which controls the stabilized soil state under

70 cyclic thermal loading. For simplicity, it is assumed to be a straight line in the $\ln v-\ln p^{\prime}$

71 space as shown in Fig. 1, where the normal compression line (NCL) and the thermal

72 stabilization line (TSL) correspond to an elevated temperature. The point $\mathrm{O}$ represents the

73 state of an NC soil specimen at the end of the first heating, and the point $\mathrm{O}^{\prime}$ represents the

74 stabilized state after several thermal cycles for the given temperature increase. The distance

75 OO' reflects the accumulated irreversible volumetric contraction of the NC soil specimen

76 after the first thermal cycle. If it equals 0 , there is no accumulation of irreversible volumetric

77 contraction. It is assumed that (1) As temperature changes the TSL shifts together with the

78 NCL which is temperature dependent according to the experimental results (e.g.,

79 Campanella and Mitchell 1968); (2) During heating, if the soil state is above the current TSL

80 there is heating induced irreversible volumetric contraction; Otherwise the soil response is

81 thermo-elastic; (3) During cooling, the soil response is thermo-elastic. Admittedly, the

82 influence of temperature on the TSL is difficult to experimentally quantify. It is a postulation

83 made by the authors to fit best the available data. In addition, the effect of

84 pre-consolidation pressure on the TSL is likely to be small. This is because experimental

85 results from Abuel-Naga et al. (2007) show that the thermally induced volume change of soil

86 is almost independent of the pre-consolidation pressure. Based on the assumptions, it can 
87 be deduced that if the distance OO' equals 0 and the slope of the TSL equals that of the NCL,

88 the proposed approach is reduced to that proposed by Hueckel and Baldi (1990) and Laloui

89 and Cekerevac (2003).

90 Vega and McCartney (2014) carried out odometer tests on the volume change of saturated

91 silt with different OCRs subjected to 4 thermal cycles $\left(18-91^{\circ} \mathrm{C}\right)$. The results are shown in

92 Fig. 2, where the open circle and solid circle represent the initial state and final state of the

93 soil specimen, respectively. Although there are some discrepancies, the final stabilized states

94 can be represented by the TSL proposed.

95 An NC soil specimen subjected to thermal cycles at constant effective stress is analysed to

96 illustrate how the proposed approach works. Fig. 3 shows the state evolution of the NC soil

97 specimen during thermal cycles. The open and solid circles represent the initial state and the

98 current state of the soil specimen, respectively. The initial state means the soil state before

99 the first thermal cycle. The dashed and solid lines correspond to the initial temperature

$100\left(\Delta T=0^{\circ} \mathrm{C}\right)$ and the elevated temperature $\left(\Delta T>0{ }^{\circ} \mathrm{C}\right)$, respectively. During the first heating,

101 both the NCL and the TSL shift downward, and the soil state stays on the NCL. Based on the

102 experimental results (e.g., Abuel-Naga et al. 2007; Uchaipichat and Khalili 2009), it is

103 reasonable to assume that soil response is thermo-elastic during cooling. For traditional

104 mechanical loading, the volume change is equivalent to the change of void ratio. However, 
105 the thermo-elastic soil deformation results in the change of soil volume, but not the void

106 ratio. This is because for thermo-elastic soil deformation the volume change of voids and soil

107 particles is proportional to each other (Khalili et al. 2010; Mašín and Khalili 2012). Therefore,

108 during cooling the soil state remains unchanged while the NCL and TSL return back to their

109 initial positions. Fig. 3(a) shows the soil state after the first thermal cycle. The corresponding

110 soil response during the first thermal cycle is qualitatively represented by the curve in Fig.

$1113(\mathrm{~b})$, which shows a continuous irreversible volumetric contraction during heating and

112 elastic response during cooling.

113 Upon re-heating, initially the soil state is below the TSL and the soil response is

114 thermo-elastic according to the assumptions made previously. As temperature increases

115 both the NCL and the TSL shift downward, with the TSL shifting more compared to the NCL.

116 As the TSL crosses the soil state point, it attracts the soil state point to move downward.

117 Therefore, there occurs more irreversible volumetric contraction. As stated in the

118 introduction, the accumulation and stabilization of irreversible volumetric contraction with

119 thermal cycles can be well characterized by the shakedown concept. According to the

120 concept of shakedown, the soil specimen approaches the stabilized state after a certain

121 number of cycles. Therefore, at the end of the second thermal cycle the soil state may stay

122 slightly above the TSL (see Fig. 3c), which controls the stabilized state of the soil subjected to

123 thermal cycles. Compared to the state after the first thermal cycle (see Fig. 3a), the vertical 
124 distance $\Delta \ln (1+e)$ between the soil state point and the TSL is reduced. Qualitatively, the

125 soil response during the second thermal cycle is demonstrated by the curve in Fig. 3(d). At

126 the beginning of heating, soil response is thermo-elastic and after temperature reaches

127 some value it turns to be thermo-plastic. It is easy to predict that after several thermal cycles

128 the soil state eventually approaches the TSL corresponding to the elevated temperature and

129 the vertical distance $\Delta \ln (1+e)$ decreases to zero as presented in Fig. 3(e). Thus, during

130 subsequent heating there is no irreversible volumetric contraction if the temperature does

131 not exceed the history maximum value. As shown in Fig. $3(f)$ the soil response turns to be

132 stabilized corresponding to the given maximum temperature increase.

\section{Mathematical formulation}

134 According to Mašín and Khalili (2012), the temperature dependent NCLs can be expressed as

$$
\ln (1+e)=N(T)-\lambda(T) \cdot \ln \left(p^{\prime} / p_{\mathrm{r}}\right)
$$

135 where $e$ is the void ratio; $p^{\prime}$ is the mean effective stress; $p_{\mathrm{r}}$ is the reference pressure $(1 \mathrm{kPa})$;

$136 \lambda(T)$ and $N(T)$ are the temperature dependent slope and intercept of the NCL, respectively.

137 They are assumed to follow

$$
\begin{gathered}
N(T)=N\left(T_{\mathrm{r}}\right)+n_{\mathrm{T}} \cdot \ln \left(T / T_{\mathrm{r}}\right) \\
\lambda(T)=\lambda\left(T_{\mathrm{r}}\right)+l_{\mathrm{T}} \cdot \ln \left(T / T_{\mathrm{r}}\right)
\end{gathered}
$$

138 where $n_{\mathrm{T}}$ and $l_{\mathrm{T}}$ are model parameters controlling the shift and slope change of the $\mathrm{NCL}$ 
139 with temperature, respectively; $T_{\mathrm{r}}$ is the reference temperature. According to the

140 experimental results (e.g., Campanella and Mitchell 1968), it is assumed that $\lambda$ is

141 independent of temperature, and thus $l_{\mathrm{T}}$ can be chosen as 0.

142 The newly introduced TSL is determined by its slope $k_{\mathrm{T}}$ and the point $\mathrm{O}^{\prime}$ as shown in Fig. 1. It

143 is expressed by

$$
\ln (1+e)=\ln \left(1+e_{\mathrm{o} \prime}\right)-k_{\mathrm{T}} \cdot \ln \left(p^{\prime} / p_{\mathrm{o}}^{\prime}\right)
$$

144 where $p_{0}^{\prime}$ is the pre-consolidation pressure; $\ln \left(1+e_{0^{\prime}}\right)$ can be calculated from

$$
\ln \left(1+e_{\mathrm{o}}\right)=\ln \left(1+e_{\mathrm{o}}\right)+c_{\mathrm{T}} \cdot n_{\mathrm{T}} \cdot \ln \left(T / T_{\mathrm{r}}\right)
$$

145 where $e_{\mathrm{o}}$ and $e_{\mathrm{o}}$, represent the void ratio corresponding to point $\mathrm{O}$ and point $\mathrm{O}^{\prime}$,

146 respectively. If the temperature is lower than the reference temperature, $e_{0}$, is assumed to

147 be equal to $e_{\mathrm{o}}$.

148 The newly introduced parameter $c_{\mathrm{T}}$ determines the accumulated volumetric contraction

149 after the first thermal cycle. If it equals 0 , there is no accumulation. The slope parameter $k_{\mathrm{T}}$

150 influences the simulated irreversible volumetric contraction of OC soil. As $k_{\mathrm{T}}$ decreases, the

151 simulated irreversible volumetric contraction of OC soil increases as it is more likely for the

152 TSL to cross the soil state point during heating.

\section{Implementation of the proposed approach}




\section{Implementation}

155 The proposed approach is combined with the hypoplastic framework. The basic hypoplastic

156 model for fine-grained soil developed by Mašín (2005) takes a nonlinear relationship

157 between the Jaumann stress rate tensor $\dot{\boldsymbol{\sigma}}$ and the Euler strain rate tensor $\dot{\boldsymbol{\varepsilon}}$ as

$$
\dot{\boldsymbol{\sigma}}=f_{\mathrm{s}}\left(\mathcal{L}: \dot{\boldsymbol{\varepsilon}}+f_{\mathrm{d}} \boldsymbol{N}\|\dot{\boldsymbol{\varepsilon}}\|\right)
$$

158 where $\mathcal{L}$ and $\boldsymbol{N}$ are fourth-order and second-order constitutive tensors, respectively; $f_{\mathrm{s}}$ and

$159 f_{\mathrm{d}}$ are scalar factors to consider the effects of stress level and void ratio, respectively; :

160 stands for double contraction and $\|\mathbf{X}\|$ denotes the Euclidean norm of the tensor $\mathbf{X}$. Detailed

161 mathematical expressions and discussions of the terms involved can be found in Mašín

162 (2005).

163 To model thermally-induced volume change of soil, Mašín and Khalili (2012) introduced a

164 thermal term $f_{\mathrm{u}} \boldsymbol{H}_{\mathrm{T}}$ into Eq. 6 as

$$
\dot{\boldsymbol{\sigma}}=f_{\mathrm{s}}\left[\mathcal{L}:\left(\dot{\boldsymbol{\varepsilon}}-\dot{\boldsymbol{\varepsilon}}^{\mathrm{TE}}\right)+f_{\mathrm{d}} \boldsymbol{N}\left\|\dot{\boldsymbol{\varepsilon}}-\dot{\boldsymbol{\varepsilon}}^{\mathrm{TE}}\right\|\right]+f_{\mathrm{u}} \boldsymbol{H}_{\mathrm{T}}
$$

$165 \dot{\boldsymbol{\varepsilon}}^{\mathrm{TE}}$ is the isotropic thermo-elastic strain rate tensor and calculated by

$$
\dot{\boldsymbol{\varepsilon}}^{\mathrm{TE}}=\frac{1}{3} \alpha_{\mathrm{s}} \cdot \dot{T} \cdot \mathbf{I}
$$

166 where $\alpha_{\mathrm{s}}$ is the volumetric thermal expansion coefficient of soil skeleton and $\dot{T}$ is the

167 temperature change rate. I is the second order unit tensor. The thermal part is coupled with 
168 the mechanical part through the void ratio, which influences the soil behaviour under both

169 thermal and mechanical loading. In addition, thermal loading can change the size of the

170 state boundary surface (Eqs. 1-2), and thus affect the soil behaviour under mechanical

171 loading. Also, mechanical loading changes the size of the state boundary surface, which

172 affects the thermal response for states at or close to the state boundary surface.

173 The mathematical expression for $\boldsymbol{H}_{\mathbf{T}}$ was derived by considering that when subjected to

174 heating at constant effective stress, the NC soil stays on the NCL as it moves with

175 temperature change (Mašín and Khalili 2012). The collapse potential factor $0 \leq f_{\mathrm{u}} \leq 1$

176 controls the heating induced irreversible volumetric contraction. The larger the collapse

177 potential factor $f_{\mathrm{u}}$ the more irreversible volumetric contraction heating can induce. For an

$178 \mathrm{NC}$ soil specimen during the first heating $f_{\mathrm{u}}$ equals 1 . When $f_{\mathrm{u}}$ equals 0 it implies the soil

179 response is thermo-elastic.

180 To implement the proposed approach within the hypoplastic framework, the key point lies in

181 modifying the collapse potential factor $f_{\mathrm{u}}$, which controls the thermally induced irreversible

182 volumetric contraction of soil. Its expression should satisfy two requirements: (1) the NC soil

183 stays on the NCL during the first heating; (2) as the soil state approaches the TSL the collapse

184 potential decreases to zero. The revised expression is expressed as Eq. 9 


$$
f_{\mathrm{u}}=\left(\frac{e-e_{\mathrm{T}}^{*}}{e_{\mathrm{T}}-e_{\mathrm{T}}^{*}}\right)^{\gamma}
$$

185 where $\langle x\rangle$ is an operator obtaining the positive part of the scalar variable $x,\langle x\rangle=(x+$

$186|x|) / 2 ; e$ is the void ratio; $e_{\mathrm{T}}$ and $e_{\mathrm{T}}^{*}$ are the void ratios on the current NCL and TSL

187 corresponding to the current mean effective stress, respectively (see point C in Fig. 1). They

188 can be calculated from Eq. (1) and (4), respectively. $\gamma$ is a new parameter controlling the rate

189 of irreversible volumetric contraction development with respect to the heating rate. As a

190 consequence, it controls the number of thermal cycles required to get the soil volumetric

191 contraction stabilized.

\section{Calibration of model parameters}

193 In this section, calibration of the three newly introduced parameters $c_{\mathrm{T}}, k_{\mathrm{T}}$ and $\gamma$ is

194 discussed. For the calibration of other relevant model parameters, please refer to Mašín

195 (2005) and Mašín and Khalili (2012). To calibrate the parameter $c_{\mathrm{T}}$, a volume change test of

196 an NC soil specimen subjected to thermal cycles until stabilization is required. Regarding the

197 slope parameter $k_{\mathrm{T}}$, test results of soil specimens with different OCRs are necessary. It can

198 be determined based on the threshold value of OCR corresponding to which there is no

199 heating induced irreversible volumetric contraction for a given temperature increase. The

200 crossing point of the thermal stabilization line for the given temperature increase and the 
201 unloading line corresponds to the threshold OCR. Ideally, experiments are required to

202 calibrate the two parameters. However, performing cyclic thermal loading test could be very

203 complex and time consuming. Based on the published experimental results (Campanella and

204 Mitchell 1968; Vega and McCartney 2014; Di Donna and Laloui 2015), a value between 0.4

205 and 0.5 is suggested for the parameter $c_{\mathrm{T}}$. Regarding the parameter $k_{\mathrm{T}}$ values from 0.01 to

2060.015 calibrated in this work can be adopted for simulations as a starting point. It should be

207 noted that $k_{\mathrm{T}}$ is supposed to be larger than the unloading parameter $\kappa$ (see Figs. $1 \& 2$ ). The

208 thermal parameters adopted in this study are determined by back-analysing the

209 experimental results, and best agreement is achieved through trial and error.

210 A sensitivity analysis was conducted to study the effect of the parameter $\gamma$ on the

211 accumulation of irreversible volumetric contraction of an NC soil specimen with thermal

212 cycles. Model parameters used are these for the soil tested by Uchaipichat and Khalili (2009)

213 (see Table 1). The four parameters $\varphi_{c}, \lambda, \kappa$ and $N$ of the mechanical part in Table 1 are the

214 same as those for the critical state theory. The parameter $r$ controls the ratio of shear

215 stiffness to bulk stiffness. Obtained results are shown in Fig. 4, which indicates that as $\gamma$

216 decreases the soil volumetric contraction stabilizes within less number of thermal cycles.

217 Specifically, for $\gamma=0.1$ it stabilizes around the fifth thermal cycle, which is consistent with

218 the experimental results (e.g., Vega and McCartney 2014). Based on the sensitivity analysis,

219 a default value of 0.1 is suggested for $\gamma$. It should be noted that the parameter $\gamma$ does not 
220 affect the irreversible volumetric contraction corresponding to the first thermal cycle. For an

221 NC soil specimen during the first heating, the soil state remains on the NCL, and thus its

222 volumetric contraction is completely determined by the parameter $n_{\mathrm{T}}$ which controls the

223 shift of NCL with temperature increase (see Eq. 2).

\section{Typical results}

225 Fig. 5 presents the computed volume change of soil specimens with 4 different OCRs $(1,1.3$,

2262 and 4$)$ subjected to 15 thermal cycles $\left(25-60^{\circ} \mathrm{C}\right)$ using model parameters for the soil

227 tested by Uchaipichat and Khalili (2009) (see Table 1). It can be seen that as the OCR

228 increases, both the irreversible volumetric contraction after the first thermal cycle and that

229 corresponding to the stabilized state decrease. For all the soil specimens the irreversible

230 volumetric contraction stabilizes within roughly five thermal cycles. For the soil specimen

231 with OCR of 4, there is no irreversible volumetric contraction, which indicates a

232 thermo-elastic soil response. It can be predicted that for soil specimen with even higher

233 OCRs, the simulated soil response is also going to be thermo-elastic. These trends are in

234 good agreement with experimental results of saturated silt with different OCRs from Vega

235 and McCartney (2014).

\section{Evaluation of the proposed approach}

237 Experimental test of remoulded illite from Campanella and Mitchell (1968) was simulated 
238 using the newly proposed approach and the approach proposed by Mašín and Khalili (2012)

239 for comparison. The soil specimen was consolidated under isotropic condition to $200 \mathrm{kPa}$.

240 Then three heating-cooling cycles (from about $60^{\circ} \mathrm{C}$ to $5^{\circ} \mathrm{C}$ ) were applied under drained

241 conditions at constant mean effective stress. The initial temperature of the soil specimen

242 was around $20^{\circ} \mathrm{C}$. Adopted model parameters are summarized in Table 1.

243 Fig. 6(a) compares the experimental results with that computed using the model proposed

244 by Mašín and Khalili (2012). It is clear that, compared to the measured results, the model

245 predicts excessive accumulation of irreversible volumetric contraction with thermal cycles.

246 Comparison of the experimental results and the computed results from the newly proposed

247 approach is shown in Fig. 6(b). Overall, it shows a reasonably good correlation between

248 them, and the excessive accumulation is well avoided. The irreversible volumetric

249 contraction accumulates at a decreasing rate. The temperature at which irreversible

250 volumetric contraction occurs increases cycle after cycle. It should be noted that the

251 proposed approach has some limitation in simulating the nonlinearity during the cooling and

252 initial re-heating process. The adopted elastic assumption during cooling and initial

253 re-heating is for simplicity. Actually, published results show somehow contradictory trend

254 during the cooling and initial re-heating process (e.g., Campanella and Mitchell 1968 and Ng

255 et al. 2016). Therefore, more research is certainly required to confirm the trend 
256 experimentally and then improve the approach further.

\section{Summary}

258 Based on the experimental results, a thermal stabilization line is introduced in the $\ln v-\ln p^{\prime}$

259 space, which controls the stabilized soil state under cyclic thermal loading. Two parameters

260 are needed to characterize the thermal stabilization line. One determines the accumulated

261 irreversible volumetric contraction for an NC soil specimen, and the other influences the

262 simulated results of OC soil. By taking use of the introduced thermal stabilization line, a

263 method is proposed to model the volume change of fine-grained soil subjected to thermal

264 cycles. The proposed method is realized within the hypoplastic framework and tested

265 against experimental results. The comparison shows that the proposed method is able to

266 simulate the overall trend of accumulation and stabilization of irreversible volumetric

267 contraction with thermal cycles.

\section{Acknowledgements}

269 The first author greatly appreciates the HKPFS scholarship offered by the Research Grants

270 Council (RGC) of the HKSAR. The financial support provided by the RGC of the HKSAR (grant

271 no. GRF 617213 and 16209415), the HKUST (grant no. FP204) and the National Science

272 Foundation of China (grant no. 51378178) are also gratefully acknowledged. 


\section{References}

Abuel-Naga, H. M., Bergado, D. T., Bouazza, A., and Ramana, G. V. 2007. Volume change behaviour of saturated clays under drained heating conditions: experimental results and constitutive modelling. Canadian Geotechnical Journal, 44(8): 942-956. doi: 10.1139/t07-031.

Baldi, G., Hueckel, T., and Pellegrini, R. 1988. Thermal volume changes of the mineral-water system in low-porosity clay soils. Canadian Geotechnical Journal, 25(4): 807-825. doi: $10.1139 / \mathrm{t} 88-089$

Campanella, R. G., and Mitchell, J. K. 1968. Influence of temperature variations on soil behavior. Journal of the Soil Mechanics and Foundations Division, ASCE 94(3): 709734.

Cekerevac, C., and Laloui, L. 2004. Experimental study of thermal effects on the mechanical behaviour of a clay. International journal for numerical and analytical methods in geomechanics, 28(3): 209-228. doi: 10.1002/nag.332.

Collins, I. F., and Boulbibane, M. 2000. Geomechanical analysis of unbound pavements based on shakedown theory. Journal of Geotechnical and Geoenvironmental Engineering, 126(1): 50-59. doi: 10.1061/(ASCE)1090-0241(2000)126:1(50). 
Cui, Y. J., Sultan, N., and Delage, P. 2000. A thermomechanical model for saturated clays. Canadian Geotechnical Journal, 37(3): 607-620. doi: 10.1139/t99-111.

Di Donna, A., and Laloui, L. 2015. Response of soil subjected to thermal cyclic loading: experimental and constitutive study. Engineering Geology, 190: 65-76. doi: 10.1016/j.enggeo.2015.03.003.

Gens, A. 2010. Soil-environment interactions in geotechnical engineering. Géotechnique, 60(1): 3-74. doi: 10.1680/geot.9.P.109.

Graham, J., Tanaka, N., Crilly, T. and Alfaro, M. 2001. Modified Cam-Clay modelling of temperature effects in clays. Canadian Geotechnical Journal, 38(3): 608-621. doi: 10.1139/t00-125.

Habiballah, T., and Chazallon, C. 2005. An elastoplastic model based on the shakedown concept for flexible pavements unbound granular materials. International Journal for Numerical and Analytical Methods in Geomechanics, 29(6): 577-596. doi: 10.1002/nag.426.

Hueckel, T., and Baldi, G. 1990. Thermoplasticity of Saturated Clays: Experimental Constitutive Study. Journal of Geotechnical Engineering, 116(12): 1778-1796. doi: 10.1061/(ASCE)0733-9410(1990)116:12(1778). 
Hueckel, T., François, B., and Laloui, L. 2009. Explaining thermal failure in saturated clays.

Géotechnique, 59(3): 197-212. doi: 10.1680/geot.2009.59.3.197.

Khalili, N., Uchaipichat, A., and Javadi, A. A. 2010. Skeletal thermal expansion coefficient and thermo-hydro-mechanical constitutive relations for saturated homogeneous porous media. Mechanics of materials, 42(6): 593-598. doi:

10.1016/j.mechmat.2010.04.001.

Laloui, L., and Cekerevac, C. 2003. Thermo-plasticity of clays: an isotropic yield mechanism. Computers and Geotechnics, 30(8): 649-660. doi: 10.1016/j.compgeo.2003.09.001.

Laloui, L., and François, B. 2009. ACMEG-T: soil thermoplasticity model. Journal of engineering mechanics, 135(9): 932-944. doi: 10.1061/(ASCE)EM.1943-7889.0000011.

Leroueil, S., and Marques, M.E.S. 1996. Importance of strain rate and temperature effects in geotechnical engineering. In Measuring and modeling time-dependent soil behavior. Edited by T.C. Sheahan and V.N. Kaliakin. Geotechnical Special Publication 61, ASCE, New York. pp. 1-60.

Mašín, D., and Khalili, N. 2012. A thermo-mechanical model for variably saturated soils based on hypoplasticity. International journal for numerical and analytical methods in geomechanics, 36(12): 1461-1485. doi: 10.1002/nag.1058. 
Mašín, D. 2005. A hypoplastic constitutive model for clays. International journal for numerical and analytical methods in geomechanics, 29(4): 311-336. doi: 10.1002/nag.416.

Ng, C. W. W., Cheng, Q., Zhou, C., and Alonso, E. E. 2016. Volume changes of an unsaturated clay during heating and cooling. Géotechnique Letters, 6(3): 1-7. doi: 10.1680/jgele.16.00059.

Nowamooz, H., Li, K., and Chazallon, C. 2016. Shakedown modeling of unsaturated expansive soils subjected to wetting and drying cycles. In E3S Web of Conferences, EDP Sciences. 9: 08007. doi: 10.1051/e3sconf/20160908007.

Sultan, N., Delage, P., and Cui, Y. J. 2002. Temperature effects on the volume change behaviour of Boom clay. Engineering Geology, 64(2): 135-145. doi: 10.1016/S0013-7952(01)00143-0.

Towhata, I., Kuntiwattanakul, P., Seko, I., and Ohishi, K. 1993. Volume change of clays induced by heating as observed in consolidation tests. Soils and Foundations, 33(4): 170-183. doi: 10.3208/sandf1972.33.4_170.

Uchaipichat, A., and Khalili, N. 2009. Experimental investigation of thermo-hydro-mechanical behaviour of an unsaturated silt. Géotechnique, 59(4): 339-353. doi: 10.1680/geot.2009.59.4.339. 
Vega, A., and McCartney, J. S. 2014. Cyclic heating effects on thermal volume change of silt. Environmental Geotechnics, 2(5): 257-268. doi: 10.1680/envgeo.13.00022.

Zhou, C., and Ng, C. W. W. 2015. A thermomechanical model for saturated soil at small and large strains. Canadian Geotechnical Journal, 52(8): 1101-1110. doi:

10.1139/cgj-2014-0229. 


\section{List of figures}

Fig. 1. Concept of the newly proposed thermal stabilization line (TSL).

Fig. 2. Validation of the proposed thermal stabilization line (TSL) by experimental results (from Vega and McCartney 2014).

Fig. 3 Schematic illustration of the proposed approach for simulating volume change of an NC soil specimen subjected to thermal cycles with a constant amplitude: (a) soil state after the first thermal cycle; (b) soil response during the first thermal cycle; (c) soil state after the second thermal cycle; (d) soil response during the second thermal cycle; (e) soil state after stabilization; (f) soil response after stabilization.

Fig. 4. Effect of the parameter $\gamma$ on simulated volume change of an NC soil specimen subjected to thermal cycles.

Fig. 5. Typical results of volume change of soil specimens with different OCRs subjected to thermal cycles from the newly proposed approach.

Fig. 6. Comparison of measured and computed results: (a) computed results from the approach proposed by Mašín \& Khalili (2012); (b) computed results from the newly proposed approach. 
Table 1. A summary of model parameters.

\begin{tabular}{|c|c|c|c|c|c|c|c|c|c|c|c|c|c|}
\hline \multirow{2}{*}{ Soil tested by } & \multirow{2}{*}{ Soil type } & \multicolumn{5}{|c|}{ Mechanical part } & \multicolumn{7}{|c|}{ Thermal part } \\
\hline & & $\varphi_{\mathrm{c}}\left(^{\circ}\right)$ & $\lambda$ & $\boldsymbol{\kappa}$ & $N$ & $r$ & $I_{\mathrm{T}}$ & $n_{\mathrm{T}}$ & $\alpha_{\mathrm{s}}\left({ }^{\circ} \mathrm{C}^{-1}\right)$ & $T_{\mathrm{r}}\left({ }^{\circ} \mathrm{C}\right)$ & $k_{\mathrm{T}}$ & $c_{T}$ & $\boldsymbol{v}$ \\
\hline $\begin{array}{l}\text { Uchaipichat \& } \\
\text { Khalili (2009) }\end{array}$ & Silt & 29.5 & 0.06 & 0.002 & 0.772 & 0.2 & 0 & -0.01 & $3.5 \times 10^{-5}$ & 25 & 0.01 & 0.5 & 0.1 \\
\hline $\begin{array}{l}\text { Campanella \& } \\
\text { Mitchell (1968) }\end{array}$ & Clay & 22 & 0.092 & 0.027 & 1.178 & Nil* & 0 & -0.009 & $3.5 \times 10^{-5}$ & 20 & Nil* & 0.4 & 0.1 \\
\hline
\end{tabular}

* This parameter is irrelevant to the simulations conducted in this study. 


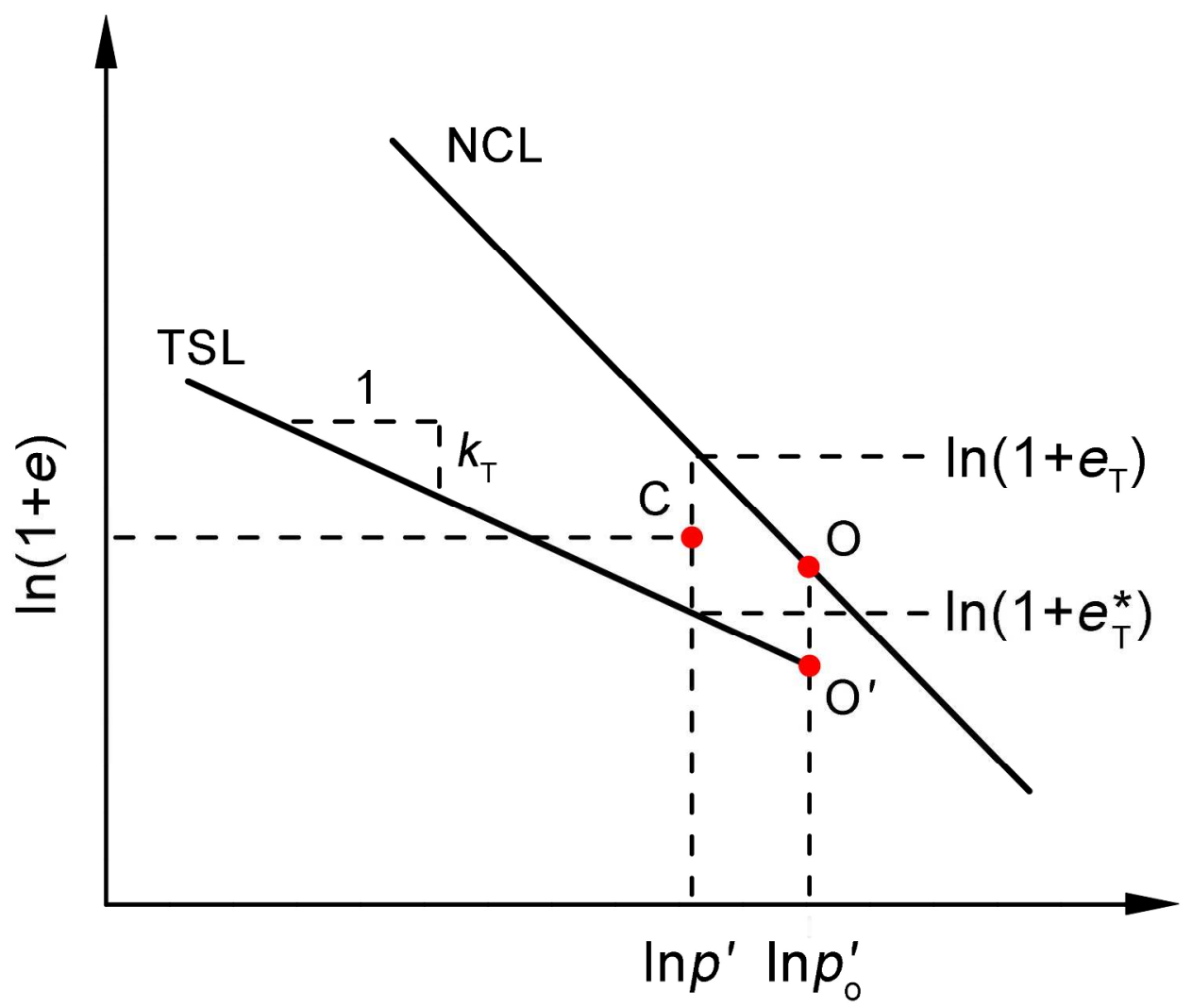

Fig. 1. Concept of the newly proposed thermal stabilization line (TSL).

$235 \times 195 \mathrm{~mm}(300 \times 300 \mathrm{DPI})$ 


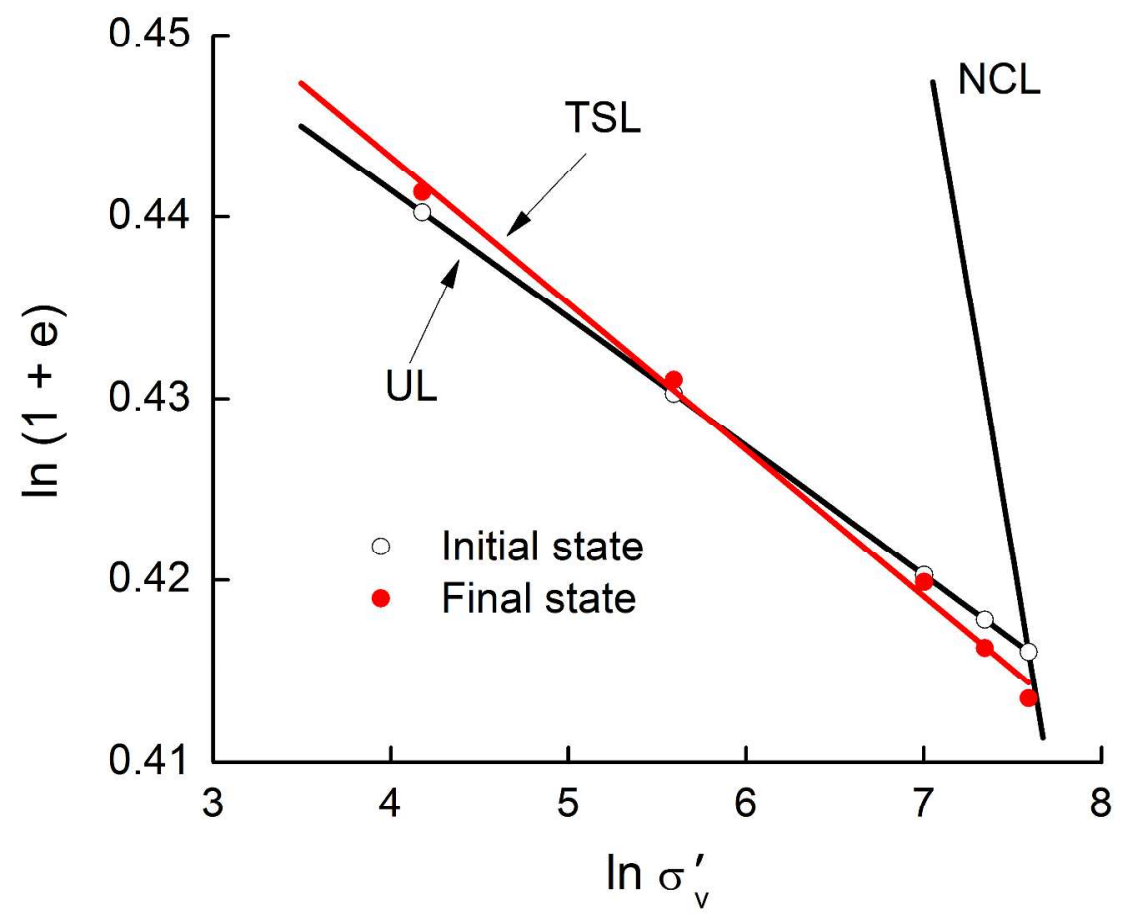

Fig. 2. Validation of the proposed thermal stabilization line (TSL) by experimental results from Vega \& McCartney (2014).

$297 \times 231 \mathrm{~mm}(300 \times 300 \mathrm{DPI})$ 


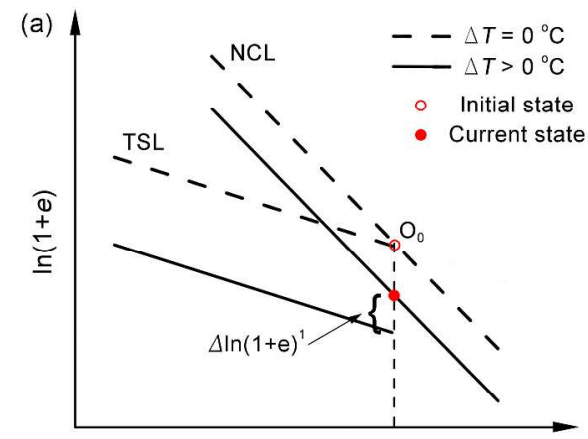

$\ln p^{\prime}$
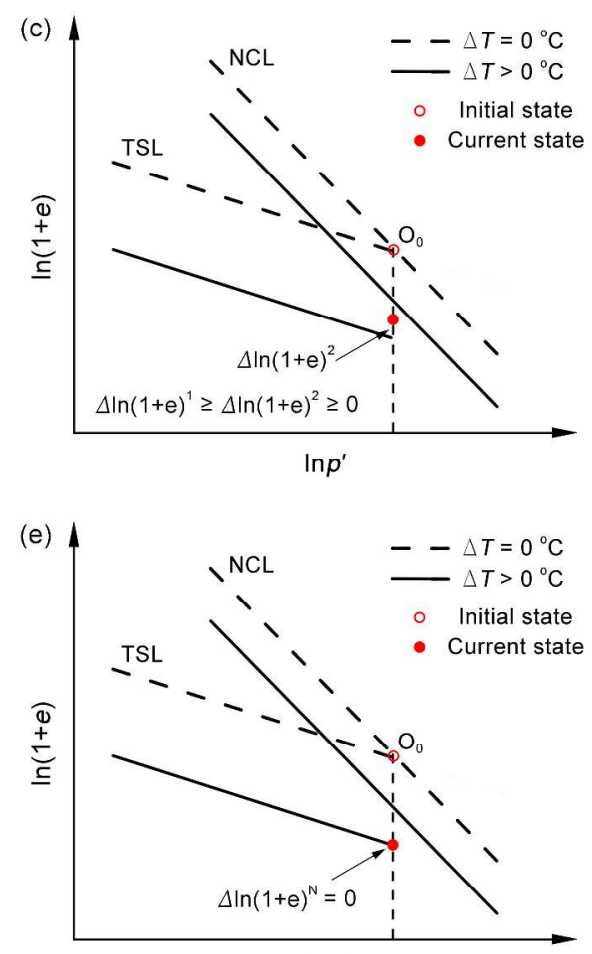

$\ln p^{\prime}$
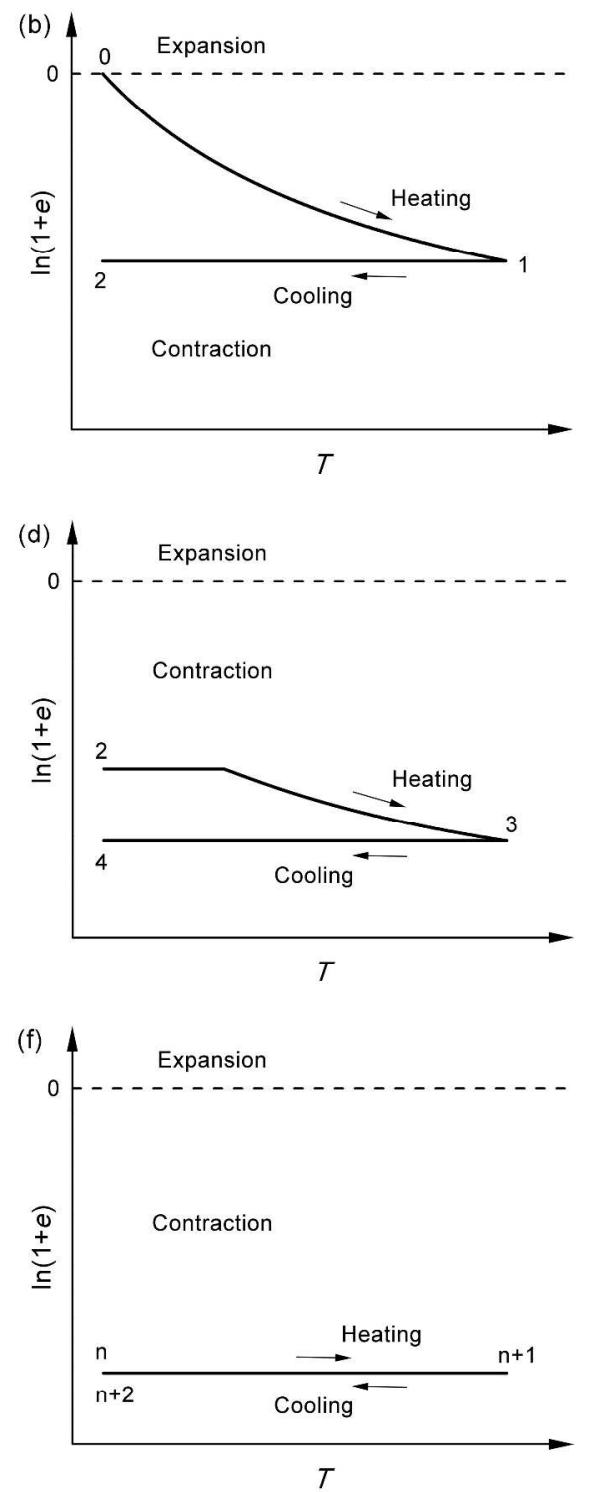

Fig. 3 Schematic illustration of the proposed approach for simulating volume change of an NC soil specimen subjected to thermal cycles with a constant amplitude: (a) soil state after the first thermal cycle; (b) soil response during the first thermal cycle; (c) soil state after the second thermal cycle; (d) soil response during the second thermal cycle; (e) soil state after stabilization; (f) soil response after stabilization.

$$
493 \times 637 \mathrm{~mm}(200 \times 200 \text { DPI })
$$




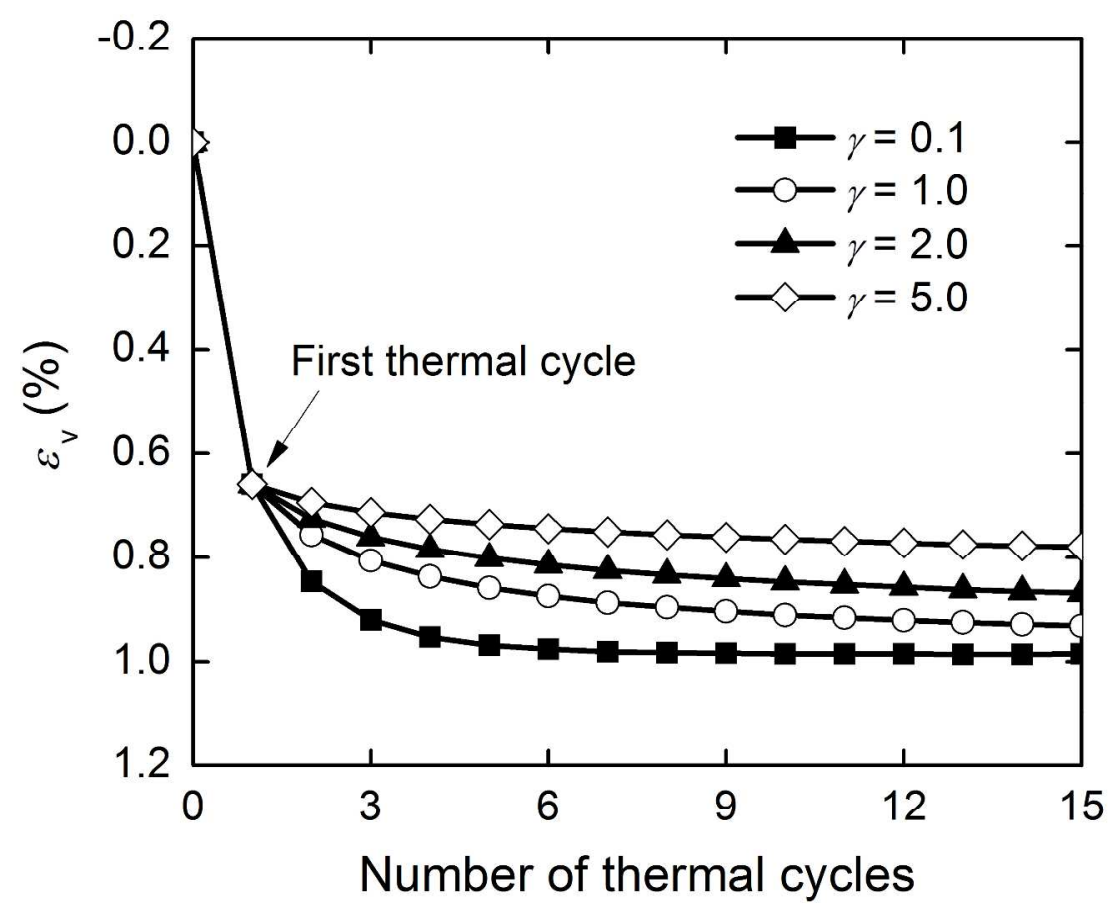

Fig. 4. Effect of the parameter $\mathrm{y}$ on simulated volume change of an NC soil specimen subjected to thermal cycles.

$297 \times 231 \mathrm{~mm}(300 \times 300$ DPI $)$ 


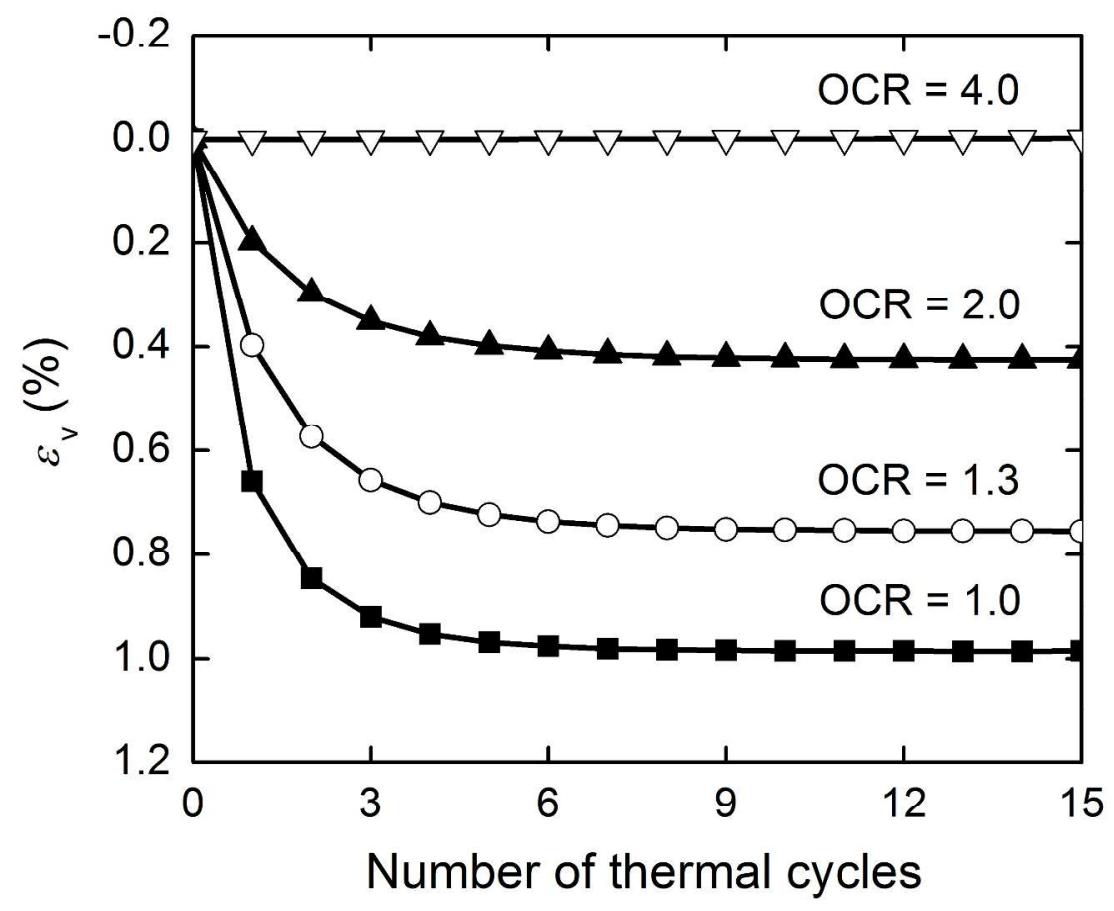

Fig. 5. Typical results of volume change of soil specimens with different OCRs subjected to thermal cycles from the newly proposed approach.

$297 \times 231 \mathrm{~mm}(300 \times 300 \mathrm{DPI})$ 

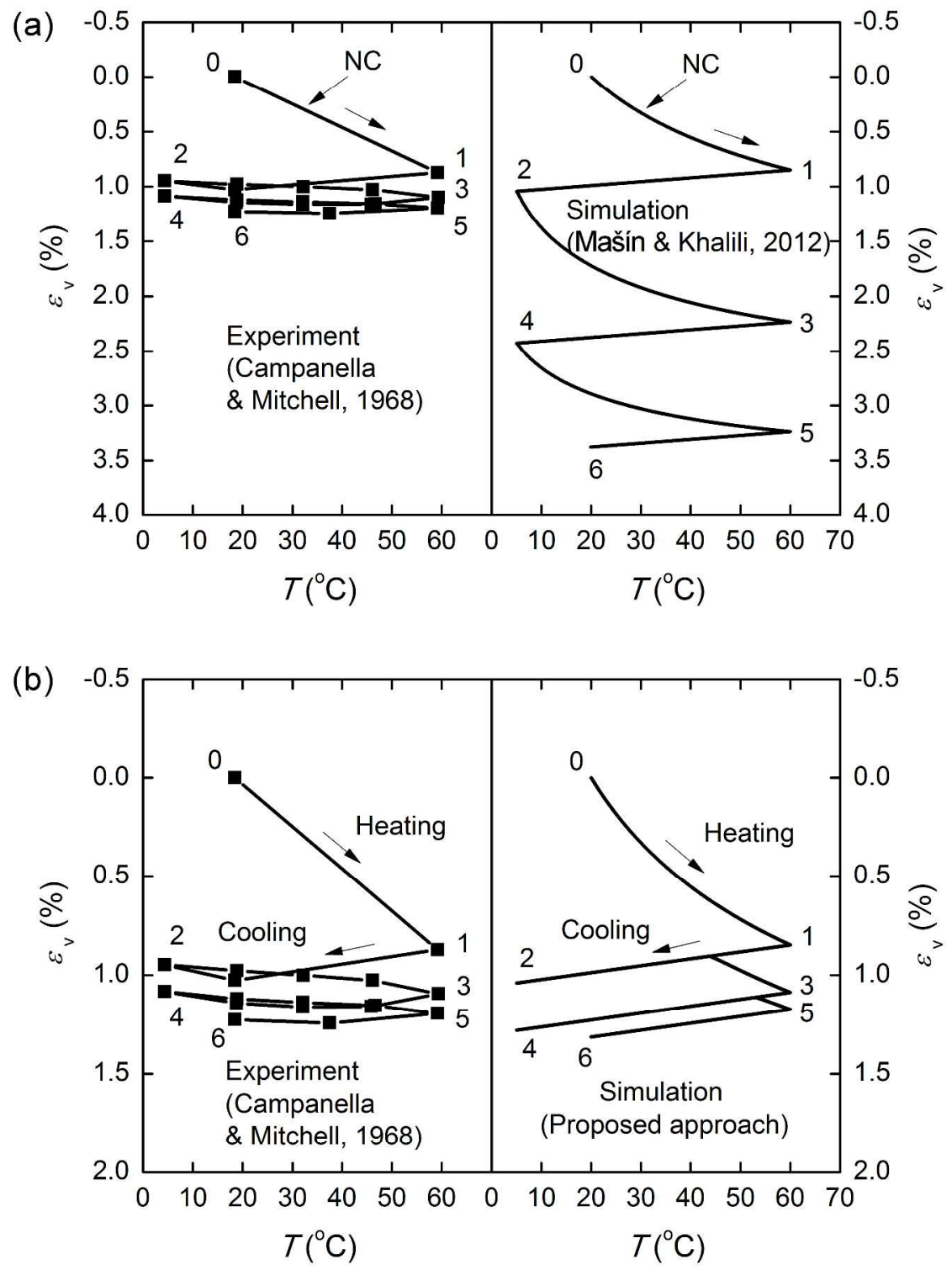

Fig. 6. Comparison of measured and computed results: (a) computed results from the approach proposed by Mašín \& Khalili (2012); (b) computed results from the newly proposed approach.

$309 \times 420 \mathrm{~mm}(300 \times 300 \mathrm{DPI})$ 